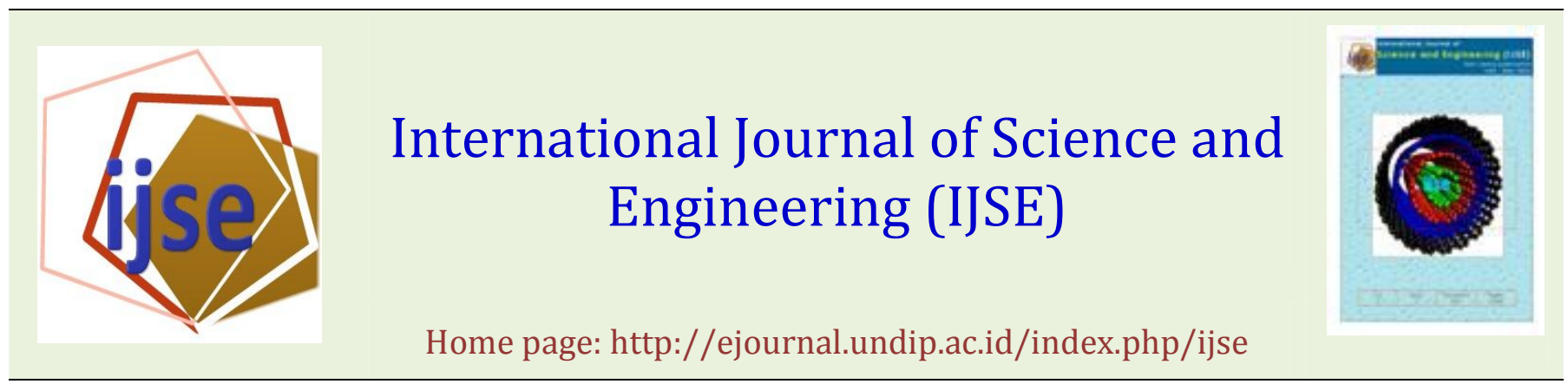

\title{
Correlation of Vapor-Liquid Equilibria for Commonly Used Binary Systems in Supercritical Fluid Extraction Processes
}

\author{
Saeid Atashrouz ${ }^{1, *}$, Hamed Mirshekar ${ }^{2, \#, ~}{ }^{1}$ Hamid Bagheri ${ }^{3}, \#$ \\ * Chemical Engineering Department, AmirKabir University of Technology (Tehran Polytechnic), No.424, Hafez Ave., P0 Box \\ 15875-4413, Tehran, Iran \\ 1. Corresponding author: s.atashrouz@gmail.com \\ \# Petrochemical Engineering Department, Amirkabir University of Technology (Tehran Polytechnic), Mahshahr Campus, \\ P.O. Box 415, Mahshahr, Iran. \\ 2. h.mirshekar69@yahoo.com \\ 3.dashchaker@yahoo.com
}

\begin{abstract}
Knowledge of the phase behavior of systems containing carbon dioxide $\left(\mathrm{CO}_{2}\right)$ are of growing importance due to the increased use of supercritical carbon dioxide as an environmentally benign solvent alternative to volatile organics in chemical processes. In the present study, a comprehensive mathematical model is developed based on the Feed-Forward Back Propagation Artificial Neural Network (FFBPANN). The model is employed for the calculation of Vapor Liquid Equilibria (VLE) of four $\mathrm{CO}_{2}$-containing binary mixtures. The mixtures include $\mathrm{CO}_{2}$ - Tertpentanol was investigated at the temperature range from 313.14 to $343.15 \mathrm{~K}$. The following mixtures including $\mathrm{CO}_{2}-$ Isobutanol at 313.2 to $353.2 \mathrm{~K}, \mathrm{CO}_{2}$ - methyl acetate at 308.15 to $328.15 \mathrm{~K}$ and $\mathrm{CO}_{2}$ - diisopropyl ether at 265.15 to $333.15 \mathrm{~K}$ were investigated as well. The related experimental data of open literature have been used to construct the model. The optimized ANN model was obtained with a hidden layer and 5 neurons in the hidden layer. The equilibrium temperature and pressure, the CO2 mole fraction in the liquid phase together with the pure component properties of the components have been selected as input variables and the $\mathrm{CO}_{2}$ mole fraction in the vapor phase as output variable. The Average Absolute Relative Deviation AARD (\%) values for the train, validation and test sets of data were obtained 0.372, 0.457 and 0.528 , respectively. These results confirm that there is a reasonable conformity between the predicted values and the experimental data. Additionally, the ability of the ANN model is examined by comparison with the conventional thermodynamic models and ANN model predicted VLE data with more accuracy.
\end{abstract}

Keywords - Vapor Liquid Equilibria, Carbon Dioxide, Supercritical Fluid Extraction, Artificial Neural Network

[How to cite this article: Atashrouz, S., Mirshekar, H. And Bagheri, H. (2013). Correlation of Vapor-Liquid Equilibria for Commonly Used Binary Systems in Supercritical Fluid Extraction Processes. International Journal of Science and Engineering, 5(1),25-30. Doi: 10.12777/ijse.5.2.1-8]

\section{Introduction}

Separation is one of the most energy intensive processes in industry. Preliminary evaluation shows that Supercritical Fluid Extraction (SCFE) can provide an effective separation with lower energy requirements than the traditional separation process [1]. From themid-1980s, the Supercritical Carbon Dioxide $\left(\mathrm{SC} \mathrm{CO}_{2}\right)+$ alcohol, ester and ether systems are of interest because of their importance as SC $\mathrm{CO}_{2}$ co solvent pairs in the biomaterials and pharmaceutical industry [2]. $\mathrm{CO}_{2}$ and alcohol systems have a high potential as supercritical co solvent pairs for separating metabolites. In separation process it leaves no solvent residues in products [3]. The high diffusivity, low viscosity, and low surface tension of $\mathrm{SC} \mathrm{CO}_{2}$ are expected to speed up mass transfer controlling chemical reactions or extractions [2]. Also, SCFE processes may be important to the alcohol industry in order to avoid the current environmental and health concerns associated with many organic solvents [1]. However, the design of this type of processes requires the knowledge of phase equilibrium diagrams over a vast range of temperatures and pressures. Although $\mathrm{CO}_{2}$ is an 
important component in SCFE, the emission of carbon dioxide has been identified as the main contributor to global warming and climate change. The challenge for modern industry is to find cost effective solutions that will reduce the release of $\mathrm{CO}_{2}$ into the atmosphere. Reduction of $\mathrm{CO} 2$ emissions can be achieved by a variety of means. A physical absorption process is one of the most important possibilities. The advantage of this method is that it requires relatively little energy. Diisopropylether, an excellent solvent, is expected to absorb $\mathrm{CO}_{2}$ [4]. So correlation of VLE data for binary mixtures that have a solvent for absorption of $\mathrm{CO}_{2}$ is important

The general and also conventional method of estimating the VLE data is based on equations of state (EOS). The EOS has been derived from strong theoretical principles and involves a number of adjustable parameters in terms of binary interaction parameters. The development of numerical tools, such as neural networks, has paved the way for other strong methods with more accuracy to estimate the VLE. It has attracted considerable interest because of its ability to capture with relative ease the non-linear relationship between the independent and dependent variables [5]. Recently, ANN has found extensive application in the field of thermodynamics and transport properties such as the estimation of VLE, viscosity, density, vapor pressure, compressibility factor and thermal conductivity and etc [6-11].

In this research, a comprehensive model based on multi-layer FFBP-ANN was developed to estimate VLE data for four binary mixtures containing $\mathrm{CO}_{2}$, the importance of which was mentioned above. The mixtures include isobutanol, methyl acetate, diisopropyl ether, tertpentanol. The developed model was trained and evaluated by using the experimental data for four binary mixtures reported by $[4,12-14]$ and pure component properties for mixtures reported by [15]. $60 \%$ of all data were assigned to the training set and $20 \%$ of all data were assigned to the validation set and the rest of the data were used as the test set .Finally, for the model validation, the prediction of the ANN model $\left(\mathrm{CO}_{2}\right.$ mole fraction in the vapor phase) was compared with the thermodynamic models from literatures and also with the experimental data.

\section{Artificial Neural Networks}

Neural networks consist of arrays of simple active units linked by weighted connections. ANN consists of multiple layers of neurons arranged in such a way that each neuron in one layer is connected with each neuron in the next layer. The network used in this study is a multi-layer feed forward neural network with a learning scheme of the BackPropagation (BP) of errors and the Levenberg- Marquardt algorithm for the adjustment of the connecting weights. Neurons are the fundamental processing element of an ANN, which are arranged in layers that make up the global architecture [16].
The main advantage of using ANNs to predict the VLE data lies in their ability to learn the relationship between the complex VLE data for different binary mixtures. The ANN input is the first layer in the network through which the information is supplied. The number of neurons in the input layer depends on the network input parameters. Hidden layers connect the input and output layers. Hidden layers enrich the network for learning the relation between input and output data. In theory, ANN with only one hidden layer and enough neurons in the hidden layer, has the ability to learn any relation between the input and output data. Transfer function is the mathematic function that determines the relation between neuron output and the network. In other words, transfer function indicates the degree of nonlinearity in the network. Practically, in the feed forward BP-ANN model some limited functions are used as transfer functions [17]. Normally, the transfer functions of all neurons in the hidden layers are similar. Also, for all neurons in the output layer, the same transfer function is used. For the prediction of phenomena, logistic transfer function is the most conventional transfer function that is used in the hidden layers, because it is very easy to differentiate the sigmoid transfer function for using in the BP algorithm [18-20]. The sigmoid transfer function is as follow:

$$
\begin{aligned}
& O_{P_{j}}(n e t)=\frac{1}{1+e^{-n e t}} \\
& n e t=\sum_{i=0}^{n-1} w_{i} x_{i}
\end{aligned}
$$

which " $n$ " in equation (1) is the number of inputs to the neuron. " $\mathrm{w}_{\mathrm{i}}$ " is the weight coefficient corresponding to the input " $\mathrm{x}_{\mathrm{i}}$ " and " $\mathrm{O}_{\mathrm{pj}}$ " is the output corresponding to the " $\mathrm{j}$ " neuron. For completion of this section, we illustrate the learning BP algorithm.

\section{ANN Training Algorithm}

The Back-Propagation Algorithm is one of Least Mean Square methods, which is normally used in engineering. In a multilayer perceptron, each neuron of a layer is linked to all neurons of the previous layer. Figure 1 shows a perceptron with a hidden layer.

Each layer output acts as the input to the next neurons. In order to train Multilayer Feed Forward Neural Network, Back-Propagation Law is used. In the first stage, all weights and biases are selected according to small random numbers. In the second stage, input vector $\mathrm{X}_{\mathrm{p}}=\mathrm{x}_{0}, \mathrm{x}_{1}, \ldots \ldots, \mathrm{x}_{\mathrm{n}-1}$ and the target exit $T_{p}=t_{0}, t_{1}, \ldots ., t_{m-1}$ are given to the network, where the subscripts $n$ and $m$ are the numbers of input and output vector, respectively. In the third stage, the following quantitative values are calculated and transferred to the subsequent layer until it eventually reaches the exit layer [21].

$$
O_{P j}=f\left[\sum_{i=0}^{n-1} w_{i} x_{i}\right]
$$

The fourth stage begins from the exit layer, during which the weight coefficients are corrected. 
$w_{i j}(t+1)=w_{i j}(t)+\eta \delta_{P j} O_{P j}$

Where " $\mathrm{W}_{\mathrm{ij}}(\mathrm{t})$ " stands for the weight coefficients from node "i" to node " $\mathrm{j}$ " in time "t", $\eta "$ is the rate coefficient, " $\delta_{P j} "$ refers to the corresponding error of input pattern "P" to the node " $\mathrm{j}$ " and " $O_{P j}$ " is the output corresponding to the j neuron. " $\delta_{P j} "$ is calculated by the following equations for exit layer and hidden layer, respectively:

$$
\begin{aligned}
& \delta_{P j}=O_{P j}\left(1-O_{P j}\right)\left(t_{P j}-O_{P j}\right) \\
& \delta_{P j}=O_{P j}\left(1-O_{P j}\right) \sum_{k} \delta_{P k} w_{j k}
\end{aligned}
$$

Here, the $\sum$ acts for k nodes on the subsequent layer after the node " $\mathrm{j}$ " [21]. In the learning process, there are several parameters that have influence on the ANN training. These parameters are the number of iterations, number of hidden layers and the number of hidden neurons. To find the best architecture of the model, best set of the aforementioned parameters based on minimizing the network output error should be chosen [22].

\section{Experimental Data}

The first step in an ANN modeling is compiling the database to train the network and to evaluate network ability for generalization. In the present study, the experimental VLE data for four binary mixtures reported by [4, 12-14] have been used for developing of the ANN model. The range of the intensive state variables (temperature $(\mathrm{T})$, pressure $(\mathrm{P})$ and $\mathrm{CO}_{2}$ mole fraction in the vapor $\left(\mathrm{Y}_{1}\right)$ and liquid $\left(\mathrm{X}_{1}\right)$ phases for each binary) and the number of data points $(\mathrm{N})$ for the ANN training were listed in Table-1. Also, the pure component properties (normal boiling point $\left(\mathrm{T}_{\mathrm{b}}\right)$, critical temperature $\left(\mathrm{T}_{\mathrm{c}}\right)$, critical pressure $\left(\mathrm{P}_{\mathrm{c}}\right)$ and acentric factor $\omega$ ) of the four binary mixture used in this work were collected from [15] and the collection was listed in Table-2.

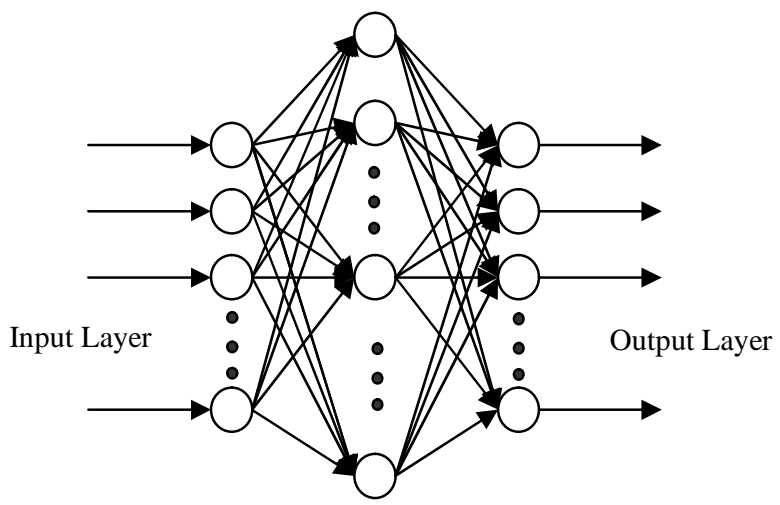

Hidden Layer

\section{Result and discussion}

\subsection{Development of the ANN Model}

An ANN model was considered for the prediction of $\mathrm{CO}_{2}$ mole fraction in the vapor phase. In order to describe the phase behavior of the four binary mixtures by one ANN model a total of eight variables have been selected in this work: four intensive state variables (equilibrium temperature, equilibrium pressure and equilibrium $\mathrm{CO} 2$ mole fractions in the liquid and vapor phases) and four pure component properties of the mixtures (critical temperature, critical pressure, normal boiling point and acentric factor). The choice of the input and output variables was based on the phase rule, practical considerations (bubble or dew point computation) and the need to describe the four binaries by only one ANN model. Therefore, the equilibrium temperature and pressure, the $\mathrm{CO}_{2}$ mole fraction in the liquid phase together with the pure component properties of the other components have been selected as input variables and the $\mathrm{CO}_{2}$ mole fraction in the vapor phase as output variable.

Using the random selection method, $60 \%$ of all data were assigned to the training set and $20 \%$ of all data were assigned to the validation set and the rest of the data were used as the test set. ANN modeling for the VLE of four binary mixtures was carried out in MATLAB ver. 7.9.0 program. Initially, the program starts with the default FFBP-ANN type (newff MATLAB function), the Levenberg-Marquardt BP training algorithm (trainlm MATLAB training function) and one hidden layer. Once the topology is specified the starting and ending number(s) of neurons in the hidden layer(s) have to be specified. The number of neurons in a hidden layer is then modified by adding neurons one at a time. In the training phase, the number of neurons in the hidden layer was important for the network optimization. However, decision on the number of hidden layer neurons is difficult because it depends on the specific problem being solved using ANN. With too few neurons, the network may not be powerful enough for a given learning task.

With a large number of neurons, the ANN may memorize the input training data very well so that the network tends to perform poorly on new test data and is called "over-fitting". To prevent the over-fitting issue, we should evaluate average absolute relative deviation percent (AARD (\%)) for train set, validation set and test set and they must be in the same order of magnitude.

Fig. 1: Perceptron structure with a hidden layer 
Table-1: Source and range of data used for developing of the artificial neural network.

\begin{tabular}{|c|c|c|c|c|c|c|}
\hline Mixture & $\mathbf{T}(\mathrm{K})$ & $\mathbf{P}(\mathbf{M P a})$ & $\mathrm{X}_{1}$ & $\mathrm{Y}_{1}$ & $\mathbf{N}$ & Ref. \\
\hline \multirow{4}{*}{$\begin{array}{c}\operatorname{CO2}(1) \\
+ \\
\text { Tertpentanol(2) }\end{array}$} & 313.4 & $4.56-7.99$ & $0.3548-0.9236$ & $0.9939-0.9768$ & \multirow{4}{*}{32} & \multirow{4}{*}{ [12] } \\
\hline & 323.4 & $4.81-9.44$ & $0.3206-0.9182$ & $0.9977-0.9583$ & & \\
\hline & 333.5 & $5.21-10.62$ & $0.3099-0.9159$ & $0.9904-0.9253$ & & \\
\hline & 343.5 & $5.33-11.44$ & $0.2409-0.8908$ & $0.9961-0.9416$ & & \\
\hline \multirow{5}{*}{$\begin{array}{c}\mathrm{CO2(1)} \\
+ \\
\text { Isobutanol(2) }\end{array}$} & 313.12 & $4.73-7.85$ & $0.3073-0.9328$ & $0.9961-0.9809$ & \multirow{5}{*}{33} & \multirow{5}{*}{ [13] } \\
\hline & 323.2 & $4.71-9.19$ & $0.2745-0.8746$ & $0.9958-0.9683$ & & \\
\hline & 333.2 & $5.25-11.35$ & $0.2893-0.8357$ & $0.9930-0.9330$ & & \\
\hline & 343.2 & $5.21-12.96$ & $0.2564-0.8426$ & $0.9932-0.9294$ & & \\
\hline & 353.2 & $4.36-14.04$ & $0.2139-0.8621$ & $0.9847-0.9412$ & & \\
\hline $\operatorname{co2}(1)$ & 308.15 & $1.06-6.86$ & $0.2806-0.9497$ & $0.9849-0.9978$ & \multirow{3}{*}{75} & \multirow{3}{*}[14]{} \\
\hline \multirow{2}{*}{$\stackrel{+}{\stackrel{+}{\text { Methyl acetate(2) }}}$} & 308.15 & $0.74-8.84$ & $0.1676-0.9802$ & $0.9832-0.9920$ & & \\
\hline & 328.15 & $0.94-6.89$ & $0.1280-0.8540$ & $0.9220-0.9857$ & & \\
\hline \multirow{5}{*}{$\begin{array}{c}\operatorname{co2}(1) \\
+ \\
\text { diisopropyl ether(2) }\end{array}$} & 265.12 & $0.682-2.478$ & $0.2795-0.7589$ & $0.9968-0.9998$ & \multirow{5}{*}{25} & \multirow{5}{*}{ [4] } \\
\hline & 273.15 & $0.547-2.526$ & $0.1831-0.6450$ & $0.9805-0.9927$ & & \\
\hline & 293.15 & $0.56-2.551$ & $0.1127-0.4907$ & $0.9653-0.9845$ & & \\
\hline & 313.15 & $0.661-2.490$ & $0.1235-0.4024$ & $0.9419-0.9729$ & & \\
\hline & 333.15 & $0.741-2.554$ & $0.1154-0.3828$ & $0.9269-0.9683$ & & \\
\hline
\end{tabular}

Table-2: Pure component properties used in this work

\begin{tabular}{lcccc}
\hline Component & $\mathrm{T}_{\mathrm{b}}(\mathrm{k})$ & $\mathrm{T}_{\mathrm{c}}(\mathrm{k})$ & $\mathrm{P}_{\mathrm{c}}(\mathrm{Mpa})$ & $\omega$ \\
\hline CO2 & 194.6 & 304.1 & 7.38 & 0.239 \\
Isobutanol & 381.0 & 547.8 & 4.20 & 0.483 \\
Tertpentanol & 375.5 & 545.0 & 3.95 & 0.592 \\
$\begin{array}{l}\text { Methyl acetate } \\
\begin{array}{l}\text { Diisopropyl } \\
\text { ether }\end{array}\end{array}$ & 330.3 & 506.7 & 4.69 & 0.569 \\
\hline
\end{tabular}

AARD (\%) was calculated from the following relation:

$$
\% A A R D=\frac{1}{n} \sum_{\mathrm{i}=1}^{\mathrm{n}} \frac{\left|Y_{1, \mathrm{i}}^{\text {Exp }}-Y_{1, \mathrm{i}}^{\text {Calc }}\right|}{Y_{1, \mathrm{i}}^{\text {Exp }}} \times 100
$$

Where " $n$ " is the number of data point, "Exp" and "Calc" superscripts stand for the experimental and calculated $\mathrm{CO}_{2}$ mole fraction, respectively. In the training process, different hidden layers and neurons were tried and finally the optimized ANN obtained for this study. The procedure begins with the logarithmic sigmoid activation function and then the hyperbolic tangent sigmoid activation function for the hidden layers and the linear activation function for the output layer. It was found out that the best neural network for this study was a network with one hidden layer and 5 neurons in the hidden layer.
Table- 3 shows the structure of the optimized ANN model. The weight matrices and bias vectors of the optimized ANN model were listed in Table-4, where $W^{\text {ih }}$ is the input-hidden layer connection weight matrix (5 rows and 7 columns), $W^{\text {ho }}$ is the hidden layer output connection weight matrix ( 1 rows and 5 columns), $b^{h}$ is the hidden neurons bias column vector ( 5 rows) and $b^{o}$ is the output neurons bias column vector $(1$ row and 1 column). Also figure 2 shows the Procedure for vapor liquid equilibrium neural network modeling with was described in this section.

\subsection{Validation of the developed ANN model}

In an optimized ANN, the AARD (\%) for the train, validation and test data sets are in the same order of magnitude, approximately. In this research, the AARD (\%) values for the train, validation and test sets of data were obtained $0.372,0.457$ and 0.528 , respectively and the network performance Mean of Squarer Error (MSE) was achieved $2.732 \mathrm{e}-3$. The ability of the model for the prediction of $\mathrm{CO} 2$ mole fraction in the vapor phase is shown in the Figure 3.

As shown, good agreement for the prediction of ANN model and the experimental data are observed.

Table-3: Architecture of the optimized ANN

\begin{tabular}{|c|c|c|c|c|c|c|}
\hline \multirow[b]{2}{*}{ Network type } & \multirow[b]{2}{*}{ Training Algorithm } & Input layer & \multicolumn{2}{|c|}{ Hidden layer } & \multicolumn{2}{|c|}{ Output layer } \\
\hline & & No. of neurons & $\begin{array}{c}\text { No. of } \\
\text { neurons }\end{array}$ & Activation function & $\begin{array}{c}\text { No. of } \\
\text { neurons }\end{array}$ & $\begin{array}{c}\text { Activation } \\
\text { function }\end{array}$ \\
\hline $\begin{array}{l}\text { FFBP-ANN } \\
\text { (newff } \\
\text { MATLAB } \\
\text { function) }\end{array}$ & $\begin{array}{l}\text { trainlm MATLAB } \\
\text { function }\end{array}$ & 7 & 5 & $\begin{array}{l}\text { tansig MATLAB } \\
\text { function }\end{array}$ & 1 & $\begin{array}{c}\text { Linear (purelin } \\
\text { MATLAB } \\
\text { function) }\end{array}$ \\
\hline
\end{tabular}


Table-4: Weights and Bias for the optimized ANN model

\begin{tabular}{|c|c|c|c|c|c|c|c|c|c|c|}
\hline \multicolumn{9}{|c|}{ Input-Hidden layer connections } & \multicolumn{2}{|c|}{$\begin{array}{c}\text { Hidden layer-Output } \\
\text { connections }\end{array}$} \\
\hline \multicolumn{7}{|c|}{ Weights } & & \multirow{2}{*}{$\frac{\text { Bias }}{b_{j}^{h}}$} & Weights & Bias \\
\hline$w_{j 1}^{i h}$ & $w_{j 2}^{i h}$ & $w_{j 3}^{i h}$ & $w_{j 4}^{i h}$ & $w_{j 5}^{i h}$ & $w_{j 6}^{i h}$ & $w_{j 7}^{i h}$ & $w_{j} 8^{i h}$ & & $w_{1 j}^{h o}$ & $b^{o}$ \\
\hline-0.5832 & -1.2629 & 1.0749 & 0.2968 & 0.2179 & 0.2620 & 0.1065 & -0.5832 & 1.4392 & 1.4586 & \\
\hline-0.8113 & -1.9963 & 0.1923 & 0.1773 & -0.3016 & -0.6284 & 0.6522 & -0.8113 & 0.2156 & -0.7053 & \\
\hline-0.0059 & -1.1340 & 0.0866 & 0.4293 & 0.6786 & 0.2396 & -0.0553 & -0.0059 & 0.0914 & -0.8753 & -0.7176 \\
\hline-0.2362 & -1.5132 & 0.3207 & -0.2431 & 0.4424 & 1.2789 & -0.2556 & -0.2362 & -0.7333 & 1.5474 & \\
\hline 0.9528 & 0.0184 & 0.7575 & -0.8585 & -0.3288 & 1.3874 & -0.3498 & 0.9528 & -0.5602 & -1.7805 & \\
\hline
\end{tabular}

Table-5: Comparison between the literature results and the present work for the entire data set

\begin{tabular}{cccc}
\hline system: $\mathrm{CO} 2+$ & thermodynamic model & AARD (\%) & AARD (\%) ANN \\
\hline Isobutanol & Peng-Robinson & 1.558 \\
Tertpentanol & Peng-Robinson & 0.518 \\
Methyl acetate & Peng-Robinson & 0.875 & 0.396 \\
Diisopropyl ether & Peng-Robinson & 1.216 & 0.408 \\
& 0.231 & 0.280 & 0 \\
\hline
\end{tabular}

a Van der Waals two-fluid mixing rule.

b Van der Waals one-fluid mixing rule.

To validate the ANN model prediction, the ability of the ANN model for the prediction of $\mathrm{CO}_{2}$ mole fraction in the vapor phase of $\mathrm{CO}_{2}$ (1) - diisopropyl ether (2) binary mixture at $293.15,313.15$ and $333.15 \mathrm{~K}$ was investigated. Then the results were compared with Zhu et al. model (Peng-Robinson EOS) [4]. The results were shown in the Figures 4-6. The Figures show good agreement of the results with the experimental data and Zhu et al. model.

Figures 7-10 show the $\mathrm{Y}_{1}-\mathrm{X}_{1}$ curves for the four $\mathrm{CO}_{2}$ binary mixtures. They include a comparison between experimental data and ANN results at different temperatures. As shown, the Figures show good agreement between experimental data and the prediction of the ANN model in different temperatures.

Also, the AARD (\%) for ANN model and thermodynamic model from [4, 12-14] is reported in Table-5. As shown, the AARD (\%) for ANN model is less than thermodynamic models and ANN model has more accuracy in comparison of other models.

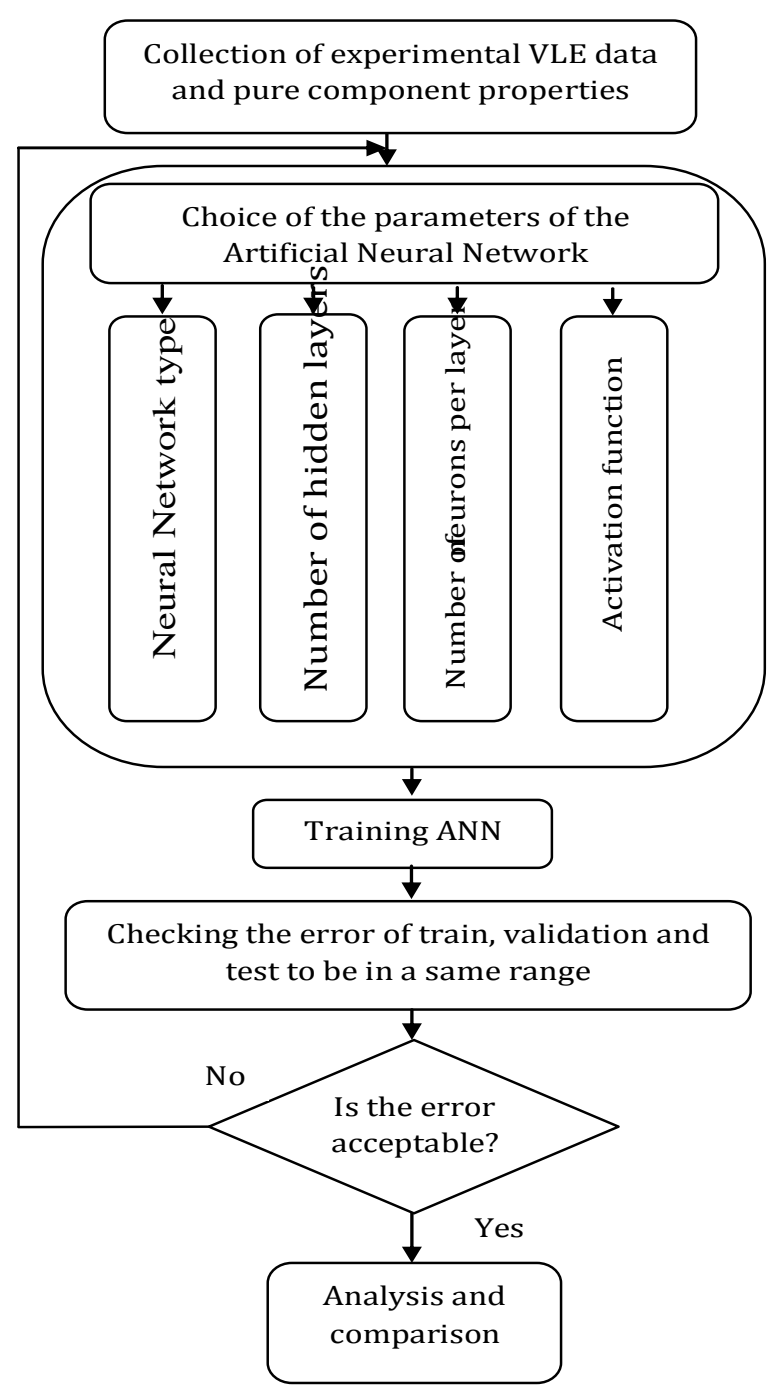

Fig. 2: Procedure for vapor liquid equilibrium neural network modeling 


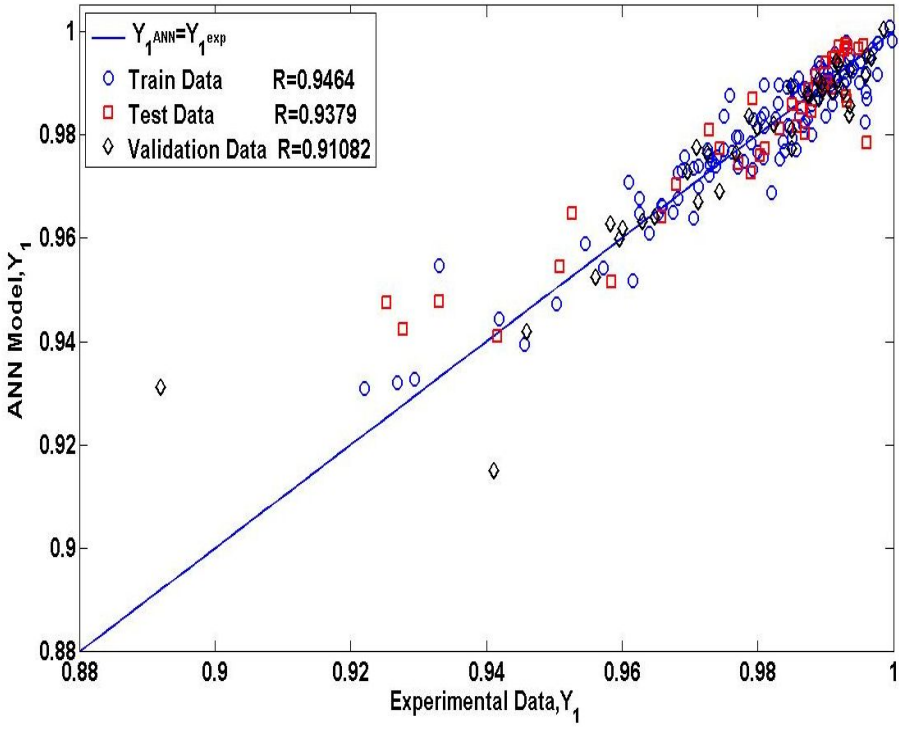

Fig. 3: Comparison of the experimental and ANN model prediction for the mole fraction of $\mathrm{CO} 2$ in four binary mixtures for all data.

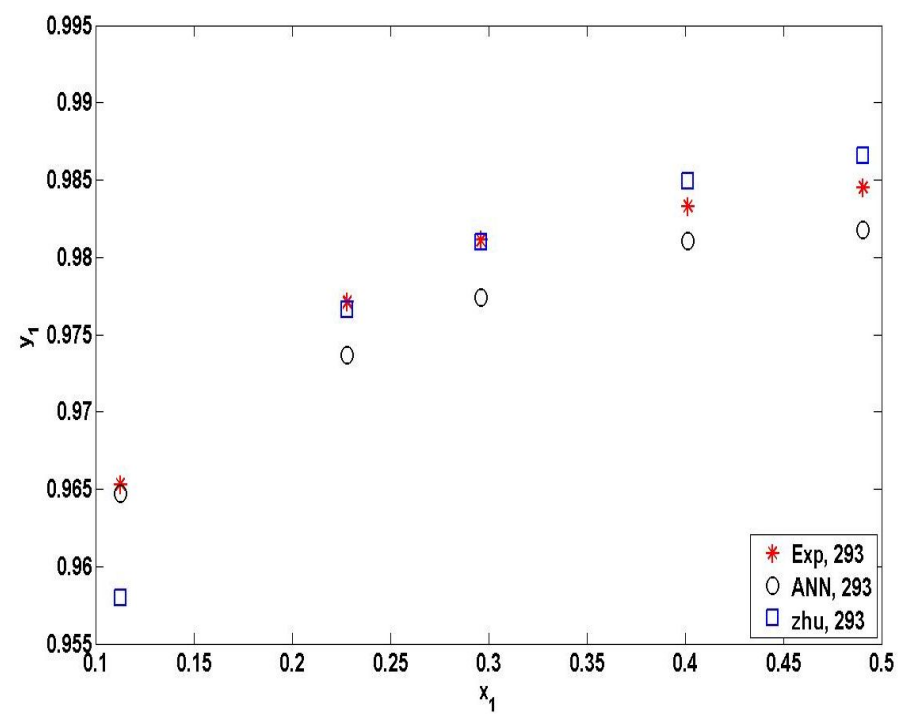

Fig. 4: $\mathrm{CO} 2$ mole fraction in vapor phase for binary system of CO2 (1)- diisopropyl (2) at $293 \mathrm{~K}$ (Experimental Data:[4], Zhu Model: [4], ANN Model: this work)

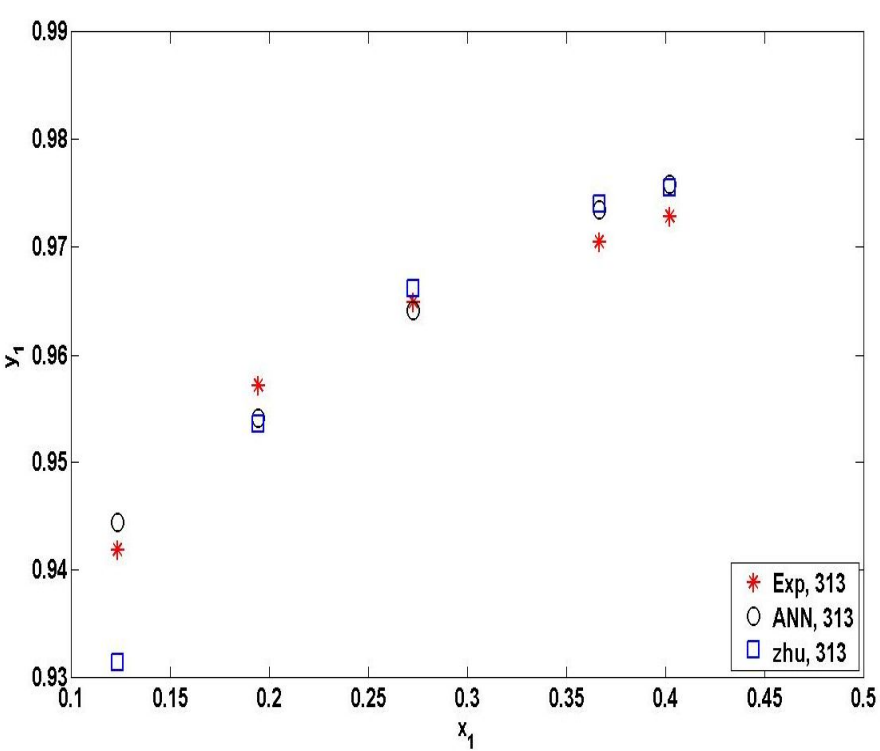

Fig. 5: $\mathrm{CO} 2$ mole fraction in vapor phase for binary system of C02(1)- diisopropyl (2) at $313 \mathrm{~K}$ (Experimental Data:[4], Zhu Model: [4], ANN Model: this work)

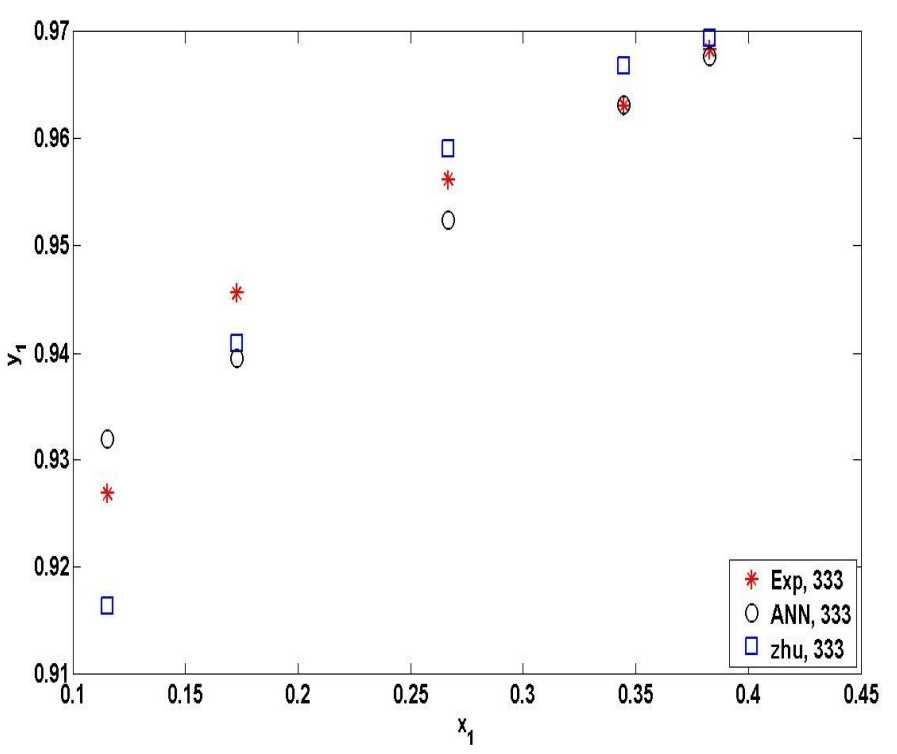

Fig. 6: $\mathrm{CO} 2$ mole fraction in vapor phase for binary system of C02(1)- diisopropyl (2) at $333 \mathrm{~K}$ (Experimental Data:[4], Zhu Model: [4], ANN Model: this work) 


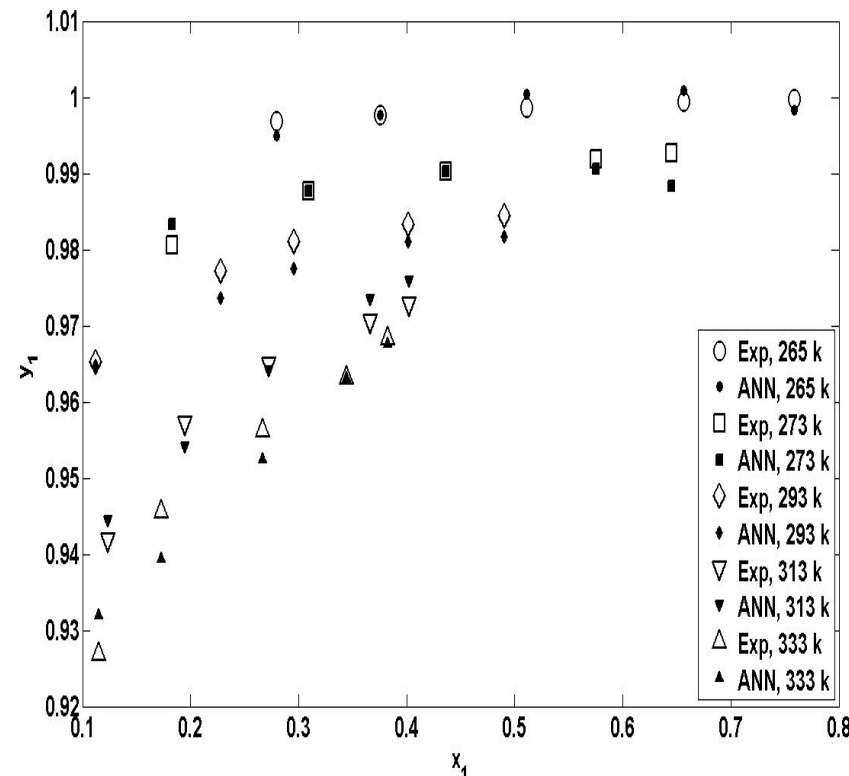

Fig. 7: $\mathrm{Y}_{1}-\mathrm{X}_{1}$ curve for the CO2(1)- diisopropyl ether(2) binary mixture at different temperatures (Exp: [4], ANN: this work)

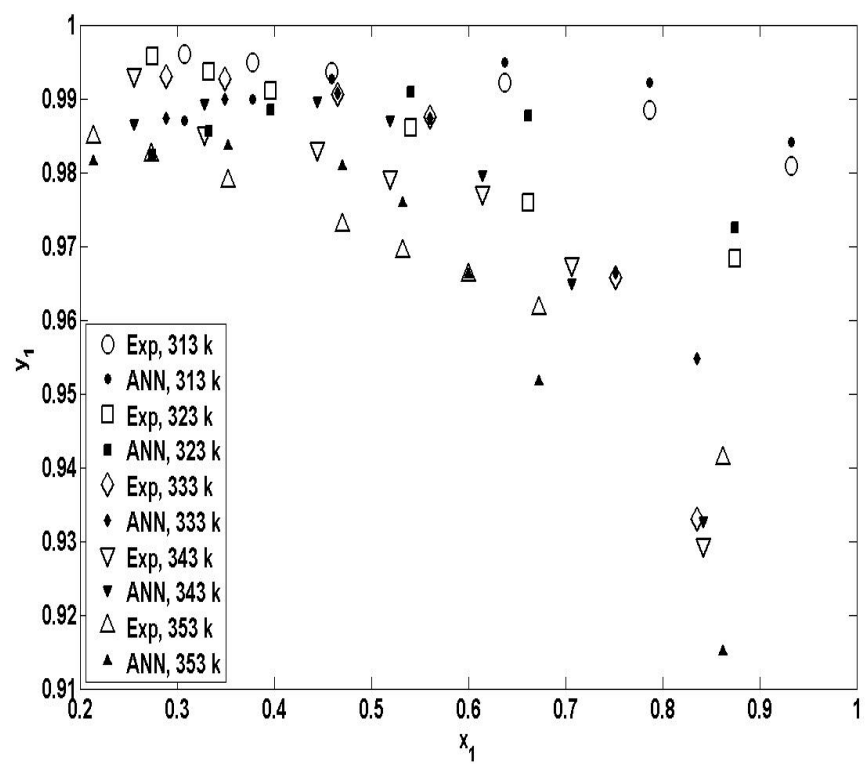

Fig. 8: $\mathrm{Y}_{1}-\mathrm{X}_{1}$ curve for the CO2(1)- Isobutanol(2) binary mixture at different temperatures

(Exp: [13], ANN: this work)

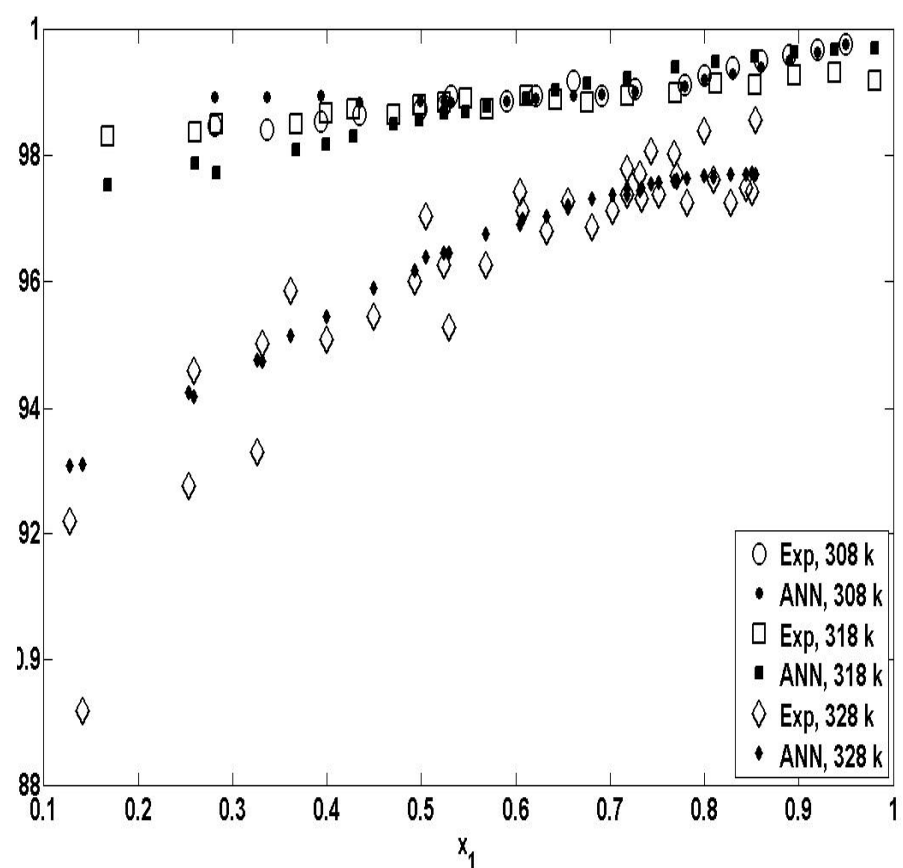

Fig. 9: $\mathrm{Y}_{1}-\mathrm{X}_{1}$ curve for the CO2(1)- Methyl acetate (2) binary mixture at different temperatures (Exp: [14], ANN: this work)

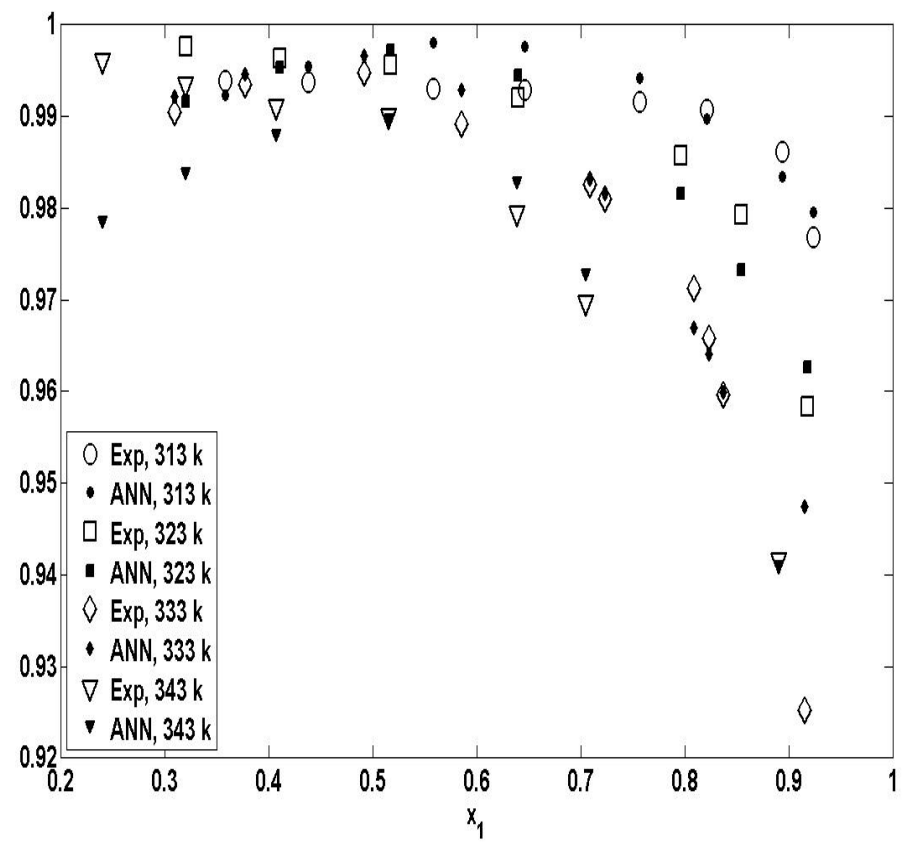

Fig. 10: $\mathrm{Y}_{1}-\mathrm{X}_{1}$ curve for the CO2(1)- Tertpentanol(2) binary mixture at different temperatures

(Exp: [12], ANN: this work) 


\section{Conclusions}

In this work, a comprehensive FFBP-ANN model was developed for the correlation of VLE data. The model was constructed for four binary mixtures containing $\mathrm{CO}_{2}$ at different temperature range. Binary systems were $\mathrm{CO}_{2}$ Tertpentanol mixture (313.14- 343.15 K), CO2 - Isobutanol (313.2- $353.2 \mathrm{~K}), \mathrm{CO} 2$ - methyl acetate (308.15- $328.15 \mathrm{~K})$, CO2 - diisopropyl ether (265.15-333.15 K). The optimized ANN model was obtained with a hidden layer and 5 neurons in the hidden layer. In the ANN training procedure, the AARD (\%) for the sets of train, validation and test data were obtained $0.372,0.457$ and 0.528 , respectively and the network performance (MSE) was achieved $2.732 \mathrm{e}-3$. It was shown that good agreement between the model correlations and the experimental data was achieved. Also, the ability of the ANN model is examined by comparison with the PengRobinson EOS and ANN model predicted VLE data with more accuracy. Finally, the advantage of the ANN model is its applicability for the four CO2-containing binary mixtures, while the thermodynamic models are used for an especially binary mixture.

\section{References}

[1] Lee, H. S., and Lee. H. (1998). High-pressure phase equilibria for the carbon dioxide-2-pentanol and carbon dioxide-water-2-pentanol systems. Fluid Phase Equilibria. 150-151:695-701. doi: http://dx.doi.org/10.1016/S0378-3812(98)00349-5

[2] Hongling, L., Rongjiao, Z., Wei X., Yanfen, L., Yongju, S., and Yiling, T. (2011).Vapor-Liquid Equilibrium Data of the Carbon Dioxide + Ethyl Butyrate and Carbon Dioxide + Propylene Carbonate Systems at Pressures from (1.00 to 13.00) MPa and Temperatures from (313.0 to 373.0) K. Journal of Chemical \& Engineering Data. 56:1148-1157. doi: http://dx.doi.org/10.1021/je101086r

[3] Lin, W., Jian-cheng, L., Hao, Y., and Kai-xun, C. (2011). Vapor-liquid Phase Equilibria for $\mathrm{CO} 2+$ Tertpentanol Binary System at Elevated Pressures. Chemical Research in Chinese Universities. 27(4):678-682.

[4] Zhu, C., Wu, X., Zheng, D., He, W., and Jing, S. (2008). Measurement and correlation of vapor-liquid equilibria for the system carbon dioxide-diisopropyl ether. Fluid Phase Equilibrium. 264:259-263. doi:http://dx.doi.org/10.1016/i.fluid.2007.11.010

[5] Ghanadzadeh, H., and Ahmadifar, H. (2008). Estimation of (vapour + liquid ) equilibrium of binary systems (tert-butanol + 2-ethyl-1hexanol) and (n-butanol + 2-ethyl-1-hexanol) using an artificial neural network. The Journal of Chemical Thermodynamics, 40:11521156. doi:http://dx.doi.org/10.1016/j.jct.2008.02.011

[6] Safamirzaei, M., Modarress, H., and Mohsen-Nia, M. (2010). Modeling the hydrogen solubility in methanol, ethanol, 1-propanol and 1butanol. Fluid Phase Equilibria, 289:32-39. doi:http://dx.doi.org/10.1016/j.fluid.2009.10.012

[7] Eslamimanesh, A., Gharagheizi, F., Mohammadi, A. H., and Richon, D. (2011). Artificial Neural Network modeling of solubility of supercritical carbon dioxide in 24 commonly used ionic liquids. Chemical Engineering Science. 66:3039-3044 doi:http://dx.doi.org/10.1016/i.ces.2011.03.016
[8] Sencan, A., Köse, I. I., and Selbas, R. (2011). Prediction of thermophysical properties of mixed refrigerants using artificial neural network. Energy Conversion and Management, 52: 958-974. doi: http://dx.doi.org/10.1016/j.enconman.2010.08.024

[9] Mohanty, S. (2005). Estimation of vapour liquid equilibria of binary systems, carbon dioxide-ethyl caproate, ethyl caprylate and ethyl caprate using artificial neural networks, Fluid Phase Equilibrium. 235: 92-98. doi: http://dx.doi.org/10.1016/i.fluid.2005.07.003

[10] Safamirzaei, M., Modarress, H. (2012). Correlating and predicting low pressure solubility of gases in [bmim][BF4] by neural network molecular modeling. Thermochimica Acta. 545:125- 130. doi:http://dx.doi.org/10.1016/j.tca.2012.07.005

[11] Bakhbakhi, Y. (2011). Phase equilibria prediction of solid solute in supercritical carbon dioxide with and without a cosolvent: The use of artificial neural network. Expert Systems with Applications, 38:11355-11362. doi:http://dx.doi.org/10.1016/j.eswa.2011.03.003

[12] Lin, W., Luo, J., Cheng, Y., and Kai-xun, C. (2011). Vapor-liquid Phase Equilibria for CO2+Tertpentanol Binary System at Elevated Pressures. Chemical Research in Chinese Universities. 27:678-682.

[13] Lin, W., Xiaosong, H., and Kaixun, C. (2009). Phase Equilibrium of Isobutanol in Supercritical C02. Chinese Journal of Chemical Engineering. 17:642-647. doi:http://dx.doi.org/10.1016/S10049541(08)60257-8

[14] Schwinghammer, S., Siebenhofer, M. and Marr, R. (2006). Determination and modelling of the high-pressure vapour-liquid equilibrium carbon dioxide-methyl acetate. Journal of Supercritical Fluids. 38:1-6 doi: http://dx.doi.org/10.1016/i.supflu.2005.11.014

[15] "Aspen Hysys 2006 Software- aspenONE".

[16] Karimi, H., and Yousefi, F. (2007). Correlation of Vapour Liquid Equilibria of Binary Mixtures Using Artificial Neural Networks. Chinese Journal of Chemical Engineering. 15: 765-771 doi: http://dx.doi.org/10.1016/S1004-9541(07)60160-8

[17] Zhang, G., Patuwo, B. E., Hu, M. Y. (1998). Forecasting with artificial neural networks: the state of the art. International Journal of Forecasting. 14:35-62. doi:http://dx.doi.org/10.1016/S0169-2070(97)00044-7

[18] Manohar, H. J., Saravanan, R., and Renganarayanan, S. (2006). Modelling of steam fired double effect vapour absorption chiller using neural network. Energy Conversion and Management. 47:22022210.

doi: http://dx.doi.org/10.1016/j.enconman.2005.12.003

[19] Malallah, A. and Nashawi, I. S. (2005). Estimating the fracture gradient coefficient using neural networks for a field in the Middle East. Journal of Petroleum Science and Engineering. 49:193- 211. doi:http://dx.doi.org/10.1016/j.petrol.2005.05.006

[20] Chakraborty, M., Bhattacharya, C., and Dutta, S. (2003). Studies on the applicability of artificial neural network (ANN) in emulsion liquid membranes. Journal of Membrane Science. 220:155-164. doi: http://dx.doi.org/10.1016/S0376-7388(03)00226-6

[21] Beale, R., and Jackson, T., (1998). Neural Computing: An Introduction. London, UK, Institude of Physics Publishing, Bristol BSI 6BE.

[22] Moghadassi, A. R., Nikkholgh, M. R., Hosseini, S. M., Parvizian, F. and Sanaeirad, A. (2011). Prediction of Vapor Liquid Equilibrium (VLE) Data for Binary Systems; Case Study: Methane/Tetrafluoromethane. ARPN Journal of Engineering and Applied Sciences. 6:100-107. 